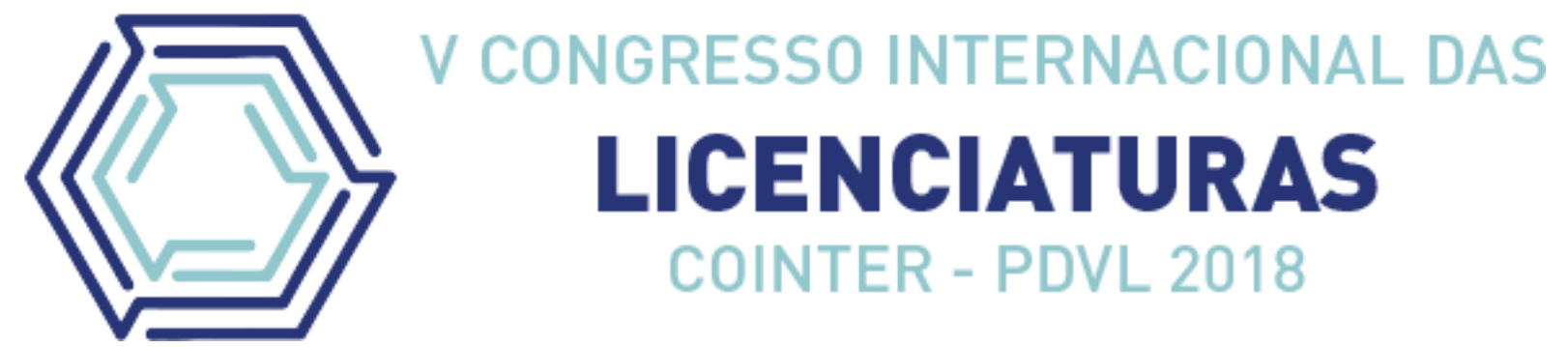

\title{
PROFESSORES DE LICENCIATURA EM QUÍMICA DO CAMPUS VITÓRIA DE SANTO ANTÃO: O QUE PENSAM A RESPEITO DO CURSO
}

\author{
Apresentação: Comunicação Oral
}

Edvan de Moura Falcão Neto ${ }^{1}$; José Henrique Duarte Neto';

DOI: $\underline{\text { https://doi.org/10.31692/2358-9728.VCOINTERPDVL.2018.00136 }}$

\begin{abstract}
Resumo
Incumbe-se essa pesquisa de levantar as opiniões que os professores que atuam na licenciatura em química do campus Vitória de Santo Antão têm formulado a respeito das práticas pedagógicas que organizam os processos de formação do licenciando em química. Busca-se compreender como os professores percebem os saberes pertinentes aos processos de formação e o movimento curricular que dá dinâmica a esses processos. O Curso de Licenciatura em Química, tende a assumir uma direção "bacharalesca", em função da trajetória da formação de professores, no Brasil. A importância de nosso objeto de pesquisa reside em contribuir com o levantamento de informações, baseadas nas opiniões dos professores-formadores que atuam no curso, de modo que venham a oferecer subsídios ao processo de reformulação curricular. Questões como: a formação que estamos oferecendo atende às exigências que a atuação profissional requer do professor de química? Os conteúdos da formação (específicos e da área) que estamos oferecendo propicia a construção de um docente competente e compromissado com a educação? O objetivo geral da pesquisa se propõe a levantar as visões que os professores-formadores têm a respeito do curso de licenciatura em química do Campus Vitória de Santo Antão. O nosso referencial teórico-metodológico requer abordar o problema de pesquisa considerando as relações sócio históricas, que favorecem os processos de produção e reprodução da existência do ser social. Com relação aos elementos procedimentais de pesquisa, definimos como campo (IFPE), especificamente o Curso de Licenciatura em Química Campus Vitória de Santo Antão. Os sujeitos da pesquisa constituem-se dos estudantes concluintes do referido curso. No que tange ao processo de coleta de informações esta ocorrerá a partir de entrevistas com os sujeitos definidos. O procedimento para o tratamento e análise dos dados, far-seá com base na análise de conteúdo. Bardin (1977) A pesquisa indicou duas categorias empíricas essenciais a primeira se apresenta na relação entre os saberes do conhecimento científico e os saberes pedagógicos. A segunda categoria revelou-se na dinamicidade do currículo. Destaca-se que este instrumento organizador dos saberes orientador das práticas de formação, transita no movimento da permanência e da transitoriedade.
\end{abstract}

Palavras-Chave: formação de professores, práticas pedagógicas, currículo

\footnotetext{
${ }^{1}$ Curso Médio Integrado a Agroindústria. IFPE -, edvanfofuxo.13@gmail.com

${ }^{2}$ Licenciatura em Química - Orientador - IFPE - henrique.duarte@vitoria.ifpe.edu.br, Instituição, e-mail
} 


\begin{abstract}
This research is investigated to raise the opinions that the teachers who work in the degree in chemistry of the campus of Vitória de Santo Antão have formulated about the pedagogical practices that organize the processes of formation of the licenciando in chemistry. It seeks to understand how teachers perceive the knowledge relevant to the training processes and the curricular movement that gives dynamics to these processes. The Degree in Chemistry tends to take a "bacharalesca" direction, due to the trajectory of teacher training in Brazil. The importance of our research object is to contribute to the collection of information, based on the opinions of the teacher-trainers who work in the course, so that they can offer support to the process of curriculum reformulation. Questions such as: the training that we are offering meets the requirements that professional performance requires the chemistry teacher? The contents of the training (specific and the area) that we are offering provides the construction of a competent and committed teacher with education? The general objective of the research is to raise the visions that the teacher-trainers have about the undergraduate chemistry course at Campus Vitória de Santo Antão. Our theoretical-methodological referential requires approaching the research problem considering socio-historical relations, which favor the processes of production and reproduction of the existence of the social being. . With respect to the procedural elements of research, we defined as field (IFPE), specifically the Degree in Chemistry - Campus Vitória de Santo Antão. The subjects of the research are students of the final course. With regard to the information collection process, this will occur from interviews with the defined subjects. The procedure for data processing and analysis shall be based on content analysis. Bardin (1977) The research indicated two essential empirical categories, the first presents itself in the relation between the knowledge of scientific knowledge and the pedagogical knowledge. The second category was revealed in the dynamics of the curriculum. It is noteworthy that this instrument organizer of the knowledge guiding the training practices, transits in the movement of permanence and transience.
\end{abstract}

Keywords: teacher training, pedagogical practices, curriculum

\title{
Introdução
}

O nosso estudo se insere no projeto de pesquisa a formação de professores no IFPE e os cursos de licenciatura: um estudo sobre o processo de implantação e as práticas curriculares cujo objeto de estudo é o conjunto de práticas pedagógicas e curriculares que contribuem na formação do futuro professor. Incumbiu-se esse plano de trabalho de buscar levantar as opiniões que os professores que atuam no curso de licenciatura em química do campus Vitória de Santo Antão têm formulado a respeito das práticas pedagógicas que organizam os processos de formação do licenciando em química. O caráter incipiente e exploratório da pesquisa atende à perspectiva de nível de formação intelectual do estudante-pesquisador e, ao mesmo tempo, intenta buscar informações para colaborar nos processos de avaliação interna do curso.

A presença das licenciaturas no IFPE tem origem na segunda metade dos anos 2000, sendo que os primeiros cursos implantados (Matemática - 2006 e Física - 2010) são oriundos do antigo 
CEFETE-PE (Uned Pesqueira). A ampliação da inserção dos cursos de licenciaturas no IFPE ocorreu logo após a criação dos Institutos Federais. De uma forma geral, é possível apontar que a ampliação da oferta de vagas nos cursos de licenciatura no âmbito do IFPE, é um dos aspectos que vai ao encontro do processo de reconfiguração da missão e dos objetivos desta nova institucionalidade, no tocante a oferta de educação superior e cursos de formação docente. Atualmente o IFPE tem 07 (sete) cursos de licenciatura na modalidade presencial e 02 (dois) na modalidade à distância. Sendo eles: Geografia e Matemática (EAD) Licenciatura em Química (Campus Barreiros, Ipojuca e Vitória de Santo Antão); Matemática e Física (Pesqueira); Licenciatura em Música (Belo Jardim); Licenciatura em Geografia (Recife).

Partimos do pressuposto de que, apesar da forte influência bacharelesca na sua formação os professores das áreas específicas, que atuam no curso, oscilam entre uma formação com forte presença dos conteúdos específicos e uma abertura aos conteúdos pedagógicos; Há uma tendência, no curso, em avançar na perspectiva de uma compreensão de formação em que os conteúdos da formação estejam articulados entre os específicos e os pedagógicos. Os nossos objetivos na pesquisa são: Levantar as visões que os professores-formadores têm a respeito do curso de licenciatura em química do Campus Vitória de Santo Antão. Identificar as tendências de formação de professores que suscitam a discussão a respeito da "bacharelização" das licenciaturas e da "pedagogização" da formação de professores. Caracterizar as opiniões que os professores que atuam na licenciatura em química, formularam a respeito das práticas pedagógicas e do currículo do curso.

O nosso referencial teórico metodológico baseia-se na crítica às concepções de formação de professores que se alicerçam nas pedagogias da racionalidade técnica e no ideário da epistemologia da prática. (DUARTE NETO, 2013) A argumentação metodológica referencia-se em uma abordagem de pesquisa que busca perceber o processo investigatório como totalidade.

Compreendemos que a importância da pesquisa está direcionada a duas questões essenciais: à permanente e necessária discussão a respeito dos processos de formação de professores, visto que a problemática educacional do Brasil, que se configura em uma crise estrutural, além de estar relacionada às decisões políticas, nas condições materiais de trabalho do professor, também está, de algum modo, relacionada à sua formação acadêmica.

A outra questão diz respeito à dinâmica de funcionamento do curso de licenciatura em química do Campus Vitória de Santo Antão que, neste momento, passa por um processo de restruturação. Assim, esta pesquisa poderá subsidiar as reflexões e decisões a serem tomadas pelos 
envolvidos neste processo. Ainda, esta pesquisa deverá contribuir na formação dos estudantes/pesquisadores envolvidos nesta atividade acadêmica.

A pesquisa indicou duas categorias empíricas essenciais a primeira se apresenta na relação entre os saberes do conhecimento científico e os saberes pedagógicos. Os professores mencionaram a necessidade do domínio desses dois campos de saberes para que a prática docente possa contribuir, significativamente, na formação do licenciando em química. A segunda categoria revelou-se na dinamicidade do currículo.

Destaca-se que este instrumento organizador dos saberes e orientador das práticas de formação, transita no movimento da permanência e da transitoriedade. Aspectos que necessitam estar sempre presentes, relacionados aos saberes e outros relacionados a novos conhecimentos que devem ser incorporados ao currículo e à prática docente. Observamos a transmissão dos conteúdos como condição fundamental para a qualidade da formação. Recoloca a questão da importância na transmissão dos conteúdos mais desenvolvidos que a humanidade logrou construir como instrumento soa processos educativos, a fim de tornar o ser humano cada vez mais humano.

\section{Fundamentação Teórica}

A crescente preocupação com a formação de professores tem contribuído para repensar os cursos de licenciatura, tanto no que diz respeito ao currículo, as práticas formativas e ao lócus de desenvolvimento de tais cursos. Neste último aspecto, destaca-se o papel estratégico que os Institutos Federais de Educação, Ciência e Tecnologia - Ifs-, criados no final de dezembro de 2008, vem assumindo como espaço de geração do aumento de oportunidades de acesso à educação superior, em virtude de sua capilaridade.

Os Institutos Federais são instituições de educação superior, básica e profissional, pluricurriculares e multicampi, especializados na oferta de educação profissional e tecnológica nas diferentes modalidades de ensino, com base na conjugação de conhecimentos técnicos e tecnológicos com as suas práticas pedagógicas, nos termos da Lei 11.892/2008. No que tange a Educação Superior, ressalta-se a expansão dos cursos de licenciatura, sobretudo na área das Ciências Exatas (Matemática, Física, Química e Biologia). Na referida lei foi estabelecido que estas instituições deveriam garantir o mínimo de $20 \%$ do total de suas vagas para atender as demandas dos cursos de licenciatura. Evidencia-se assim, o compromisso dos IFs com a formação de professores para a educação básica (com destaque para a área de ciências da natureza e mesmo para a matemática), essa opção foi definida, tendo em vista a carência de professores nas referidas áreas, conforme estudo realizado pelo MEC em 2009. 
Diante deste cenário, pode-se observar que o processo de implantação das licenciaturas apresenta um caráter singular, haja vista que as instituições que hoje compõem o IFPE têm uma tradição na formação profissional, especialmente na área industrial e na agropecuária. Ressaltam-se ainda, as políticas estabelecidas para Educação Profissional que foram orientando os rumos dos IFs quanto à obrigatoriedade da oferta de cursos de licenciatura. Importante ressaltar que a formação de professores não é algo novo no cenário da Rede Federal de Educação Tecnológica. Franco e Pires (2010) demonstram que desde a década de 1980 já são identificáveis alguns traços da formação de professores em Institutos Federais, na época, antigos Cefet. Sobre esta questão, os autores destacam a experiência do Cefet Maranhão, em 1987 com a implantação da Licenciatura em Matemática. Todavia, os referidos autores enfatizam que a formação de professores só veio assumir um caráter de política pública no âmbito das instituições de educação tecnológica com a aprovação do Decreto 3.462/2000, que dentre outros aspectos trouxe autonomia aos Cefets para "a criação de cursos e ampliação de vagas nos níveis básico, técnico e tecnológico da Educação Profissional, bem como para implantação de cursos de formação de professores para as disciplinas científicas e tecnológicas do Ensino Médio e da Educação Profissional". Em atendimento ao disposto no Art. $8^{\circ}$ da Lei 11.892 o Instituto Federal de Pernambuco - IFPE, privilegiou a oferta de cursos de licenciatura nas áreas das ciências da natureza e da matemática e suas tecnologias, atendendo a um dos chamados do MEC, face ao problema de escassez de professores, sobretudo no ensino médio. Neste contexto, o IFPE, que há poucos anos apresentava à oferta voltada, principalmente para os cursos técnicos, no ensino médio e, tecnológicos, em nível de graduação precisou se reordenar do ponto de vista de infraestrutura e quadro de pessoal para atender às demandas dos cursos de licenciaturas e dos demais cursos superiores que foram implantados no período de 2010-2011. Atualmente o IFPE tem 07 (sete) cursos de licenciatura na modalidade presencial e 02 (dois) na modalidade à distância. Sendo eles: Geografia e Matemática (EAD) Licenciatura em Química (Campus Barreiros, Ipojuca e Vitória de Santo Antão); Matemática e Física (Pesqueira); Licenciatura em Música (Belo Jardim); Licenciatura em Geografia (Recife).

A presença das licenciaturas no IFPE tem origem na segunda metade dos anos 2000, sendo que os primeiros cursos implantados (Matemática - 2006 e Física - 2010) são oriundos do antigo CEFETE-PE (Uned Pesqueira). A ampliação da inserção dos cursos de licenciaturas no IFPE ocorreu logo após a criação dos Institutos Federais. De uma forma geral, é possível apontar que a ampliação da oferta de vagas nos cursos de licenciatura no âmbito do IFPE, é um dos aspectos que vai ao encontro do processo de reconfiguração da missão e dos objetivos desta nova institucionalidade, no tocante a oferta de educação superior e cursos de formação docente. 
Considerando que uma concepção de formação de professores só se materializa em suas finalidades no âmbito das práticas curriculares e a prática requer, como uma de suas estruturantes, a concepção referida, torna-se importante campo de pesquisa, perceber como esses elos, indissociáveis da formação docente dialogam, nesse lócus da formação, que são os IFs.. Do mesmo modo, o processo de construção do conhecimento escolar só tem sentido no âmbito das práticas curriculares, orientados, ambos, por uma concepção de formação, como pela maneira a partir da qual se organiza o trabalho pedagógico. Tais questões instigam-nos a investigar a formação de professores no IFPE, considerando-se aspectos relativos ao processo de implantação dos cursos de Licenciatura, bem como as práticas curriculares e pedagógicas.

Assim, indagamos: como se deu o processo de implantação dos cursos de licenciatura do IFPE? Que fatores estão imbricados ao processo de implantação das licenciaturas? Como se caracteriza, grosso modo, as práticas curriculares nos IFs nos cursos de formação de professores? Qual a relação entre a concepção de formação de professores e essas práticas curriculares? De que modo a concepção de formação de professores e as práticas curriculares incidem na construção e na natureza do conhecimento escolar, nesses espaços de formação?

Assim, nos interessa investigar as políticas e as práticas de formação de professores para a educação básica, implementadas no IFPE, a fim de identificar os fatores facilitadores e inibidores desse processo, bem como as práticas curriculares desenvolvidas e suas implicações para formação do futuro docente.

Compreender os processos de organização do trabalho educativo e de construção do conhecimento escolar, que dá forma e conteúdo a formação docente e o diálogo que estabelece com as reais necessidades das redes de ensino em que, futuramente, os licenciandos deverão atuar, como profissionais da educação.

\section{Metodologia}

A natureza de nossa pesquisa é qualitativa. O nosso referencial teórico-metodológico procurou abordar o problema de pesquisa considerando as relações sócias históricas, que favorecem os processos de produção e reprodução da existência do ser social. Desse modo, foi importante um referencial teórico-metodológico que percebesse o processo de pesquisa como totalidade, que pudesse tomar os seus diversos aspectos em estreita relação de dependência e de determinações recíprocas. Optamos por uma abordagem dialética, por compreender que para dar conta da complexidade da realidade com suas múltiplas dimensões, precisamos utilizar um método que tenha as suas categorias de análises extraídas da própria realidade, apreendendo e interpretando as suas relações, o seu movimento e as mudanças inerentes à sua natureza (LEFEBVRE, 1979) para que a 
ela retorne, em um processo de construção e reconstrução do objeto de estudo. Um método que permita ordenar, disciplinar e sistematizar o processo de trabalho, sendo capaz de conceber esta realidade em sua totalidade, mas que também não ignore, por outro lado, aspectos que lhes são singulares, particulares e que favoreça relações entre aspectos de natureza específica e geral, entre objetividade e subjetividade (FRIGOTO, 2000). Com relação aos elementos procedimentais de pesquisa, definimos como campo $O$ Instituto Federal de Educação, Ciência e Tecnologia de Pernambuco (IFPE), especificamente o Curso de Licenciatura em Química - Campus Vitória de Santo Antão. Os sujeitos da pesquisa constituíram-se dos professores que atuam no curso. No que tange ao processo de coleta de informações esta ocorreu a partir de entrevistas semiestruturadas com os sujeitos definidos.

O procedimento para o tratamento e análise dos dados, deu-se com base na análise de conteúdo. No interior da análise de conteúdo, usaremos o procedimento da análise temática, levando em consideração os "polos cronológicos” de que nos fala Bardin (1977): 1) a pré-análise; 2) a exploração do material; 3) o tratamento dos resultados.

O trabalho de produção do conhecimento se realizou com base em reuniões de estudos, a partir das leituras sistemáticas e orientadas da bibliografia definida, o que favoreceu a discussão teórica e conceitual e propiciou a socialização dos conhecimentos a serem construídos. Os encontros semanais ocorreram com a finalidade de fazer uma exposição reflexiva das leituras realizadas, para em momento oportuno, apresentar as informações coletadas, bem como proceder com o registro do conteúdo discutido, para futura elaboração de relatórios e textos (artigos) que contemplassem as análises e os resultados de pesquisa.

\section{Resultados e Discussão}

A importância da realização deste trabalho reside na capacidade da crítica, que a pesquisa científica pode suscitar no sujeito envolvido no processo investigatório e a possibilidade de comprometimento, com a construção de uma educação de qualidade, em todos os níveis. A construção do conhecimento científico, em última instância, justificou ao nosso ver, o desenvolvimento desta pesquisa. Esperávamos, ainda, que o conhecimento construído nesta pesquisa pudesse subsidiar as reflexões existentes no âmbito do curso de licenciatura em química, envolvendo os sujeitos que constroem a formação (docentes, discentes e técnicos) cuja finalidade está nos processos de restruturação curricular, como exigência da Resolução n. 2 , de $1^{\circ}$ de julho de 2015, a qual define as Diretrizes Curriculares Nacionais para a formação inicial em nível superior, bem como trata da formação continuada e a valorização do magistério. 
A entrevista semiestruturada foi realizada com quatro (04) professores do curso de licenciatura em química, composta por quatro (04) questões. Os professores selecionados são atuantes na área de educação envolvendo alguma especificação na área de química, que denominamos de "Professor da Área Específica - PAE) e os demais "Professores da Área Pedagógica - PAP), deste modo a identificação dos professores ficou sendo: PAE1; PAE; PAP1; PAP2. A entrevista foi estruturada de maneira a não prejudicar a imagem de nenhum servidor ao mesmo tempo em que exigiu uma reflexão prévia sobre cada assunto abordado e uma ampla possibilidade de respostas possibilitando até "sinergias" entre elas. Nenhum dos entrevistados se recusou a aceitar os termos de privacidade propostos, como parte da integridade das informações.

A partir do procedimento de análise das entrevistas, podemos destacar quatro temáticas: 1 . Saberes; 2. Currículo; 3. Prática Pedagógica; 4. Práticas e conteúdos ausentes na formação. No âmbito da construção das categorias empíricas mencionadas acima, sugeridas a partir das questões que compuseram a entrevista, destacamos os seus desdobramentos com base na regularidade das ideias e construções evocativas. Assim, apresentaremos as regularidades surgidas que denotam posicionamentos e compreensões em relação aos processos formativos.

Em se tratando da primeira temática "saberes" foi recorrente a ideia de "conjunção de saberes", mencionados pelos quatro professores entrevistados, com uma pequena variação. Todos afirmaram a necessidade de estar presente nos processos formativos desenvolvidos pelos professores o que denominam de "saberes da área/específico", aliados aos "sabres pedagógicos", identificados com a profissão docente. Deste modo, destacaram os docentes: "A conjunção de dois saberes, os saberes que estão associados a docência em si que engloba desde a parte de psicologia, a parte de didática, organização, currículo, todas as questões associadas a aprendizagem e a parte especifica que é o conhecimento específico em química. " (PAE01).

Esta fala está, de algum modo, presente no discurso dos demais professores entrevistados. Para além destes saberes o PAP01, amplia este campo, acrescentando outra dimensão da relação:

Todo professor além de ter e possuir domínio de conhecimentos específicos da sua área, precisam também ter o domínio das questões pedagógicas, que seriam justamente essas relações...[...] as relações afetivas, do "trato com o conteúdo", da condução de aula e fazer com que os alunos entendam o conteúdo proposto...[...] A aprendizagem acontece quando o aluno consegue entender a importância e a necessidade de entender aquele determinado assunto para sua vida, ou seja, quando o aluno consegue fazer a relação desse assunto no seu processo de formação profissional e formação humana que é o que a gente chama de "dar significado", então os saberes docentes não são aqueles presos apenas nas questões específicas, mas naqueles relacionados a como eu trato dos meus alunos, como meus alunos me tratam, como eu me reconheço como professor e como eu reconheço os meus alunos. 
Com relação a segunda temática a categoria currículo surge a partir da mesma lógica de construção da anterior, como produto da questão de entrevista e como discurso do professor entrevistado. A construção se deu observando que o conteúdo da categoria evocada pelos professores a percebem como uma categoria em movimento, no sentido de estar sempre em construção. Assim, percebem o currículo como prática e enquanto tal sujeita às contradições do movimento da realidade. Ou seja, compreendem o currículo como algo dinâmico em que apresenta elementos de constâncias e elementos de passagem. Deste modo, a respeito do currículo do curso e suas possibilidades de uma formação adequada, assim se expressou o PAE01 "Ele sempre vai precisar estar sendo aperfeiçoado porque a gente vive numa sociedade que ela é dinâmica..." Mais enfática foi a fala de PAP01, se expressou:

Claro que ele não vai responder a todos os desafios, nem esse curso em nenhum outro curso... O "nosso" curso de química da instituição (do IFPE - campus vitória) é um curso muito sólido, muito consistente na perspectiva da preparação do professor porque é um curso bem equilibrado no sentido do "trato dos conhecimentos específicos da química" como no "trato dos conhecimentos do ser professor", ou seja, ele tem uma preparação consistente no sentido de ser professor de química.

Entretanto, percebemos que a dinâmica do currículo, como movimento inerente à esta categoria envolve, segundo o PAP02, outra característica importante, a de ser "adaptável" às exigências de formação que vão surgindo, “o currículo precisa ser flexível e quando a gente se reúne e analisa o currículo a gente observa que ele é sempre modificado e acaba por se adaptar às novas realidades que vão surgindo no decorrer do ano. "

Com relação a terceira temática, definida como Prática Pedagógica, percebemos ser constante na fala dos professores entrevistados a preocupação com uma prática planejada. Este critério entendemos ser fundamental para propiciar uma formação profissional mais consistente e articulada. Neste ítem as aproximações ocorrem na necessidade de ser previamente planejada. Os distanciamentos estão na forma como o planejamento deve nortear a prática e a que dimensão do currículo este planejamento se vincula. Há na fala dos professores, algumas que entendem o planejamento em uma relação quase que de subordinação ao projeto político pedagógico do curso, obrigando-se ao conteúdo e pensando em uma maior liberdade metodológica, como afirma o PAE01 -

A abordagem do conteúdo é que você tem uma maior liberdade pra tratar uma vez que os conteúdos já são pré-determinados dentro da ementa, então, a liberdade que você tem é exatamente na abordagem, de você dar uma nova "roupagem" a determinados conteúdos que são obrigatórios aos alunos na formação docente e, obviamente, tanto a avaliação quanto a organização das disciplinas devem estar conectadas ao conteúdo e para além desse conteúdo com o que se propõe o projeto pedagógico do curso. 
Entendendo o planejamento para além de instrumento de organização da prática pedagógica, surgiu entre os professores entrevistados uma compreensão sobre planejamento para além do aspecto instrumental. Neste sentido, é importante a fala docente PAP01:

Para eu atuar como professor eu tenho que planejar, para eu planejar eu tenho que saber o que é que vai ser tratado e como eu vou abordar, pois não é só o fazer, mas qualquer ação que se tenha como professor em sala de aula, que o ato educacional é um ato intencional porque é um ato político de tomada de decisão... [...]porque o professor precisa planejar pois quando eu planejo uma aula ou qualquer ação e faço de acordo de como eu penso, então quando a gente está falando de didática, que é muito forte, "que tipo de professor é esse?”, “que tendência ele segue?", “qual é a linha de seu raciocínio?”,

A quarta categoria está relacionada ao movimento geral do curso que envolve diversos aspectos da formação. Vários desses aspectos já mencionados aqui, quando atuam de forma articuladas contribuem de forma significativa para a formação de qualidade. Neste sentido, buscando identificar os limites nos processos formativos, formulamos uma questão de entrevista que buscasse identificar as "ausências". Deste modo, surgiu a temática "práticas e conteúdos ausentes na formação. " Nesta temática/categoria observamos na fala dos professores uma constância no que tange a reivindicar mais elementos da "prática". Ao que tudo indica esta dimensão da formação está relacionada a aspectos metodológicos, como podemos verificar na fala de PAE01

Eu acho que um aspecto que nós deixamos a desejar no currículo é uma maior utilização de recursos "extra sala de aula" o nosso currículo e a escola de uma forma geral anda muito presa a paradigmas do século passado, a sala de aula não mudou muito do ponto de vista real, não usamos hoje as tecnologias da informação quando elas permitem ao professor, onde entra a questão da formação, estender essa sala de aula para outros ambientes que não seja o ambiente físico da sala de aula e isso a gente peca no nosso currículo de não ter uma abordagem mais incisiva, um peso maior na formação dos licenciandos, na preparação deles para poder tomar vantagem das tecnologias da informação.

Esta fala é corroborada pelo docente PAE02

... as atividades práticas. [...]eu acredito que os nossos alunos, no currículo atual, eles carecem um pouco de formação prática e vivência no laboratório de química uma vez que eles são preparados tanto para atuar no ensino médio quanto para atuar no ensino técnico onde se tem uma carga muito pesada de laboratório.

Entretanto, destacamos uma fala que transcende aos aspectos meramente epistemológicos, conceituais e assumem, de algum modo, uma conotação procedimental, atitudinal. Destacamos por entender que a formação de professores, os conteúdos não explicitados, mas que se refletem na prática, algumas vezes inconscientes do professor, são também “conteúdos de formação". Neste sentido, destacamos a fala docente abaixo:

Essa é uma pergunta que requer um pouco mais de reflexão...[...] dessas situações e ai no caso acaba se tornando ausentes certas questões, mas uma questão que posso elencar não como ausente, mas que merecia uma atenção especial é a questão interpessoal, do contato como o outro, pois é como eu digo: "você ta trabalhando pra ser professor, você vai trabalhar com gente, então se você não gosta de gente, ou não sabe como trabalhar com 
gente, ou não quer trabalhar com gente, você está no curso errado e tem que se achar!", porque trabalhar com gente não é fácil e o tempo todo, quando se está falando em educação, você está trabalhando com gente seja seus alunos, outros professores, seja os pais dos seus alunos... (PAP01) (grifos nossos)

\section{CONCLUSÕES}

A nossa pesquisa indicou algumas categorias empíricas essenciais, tomadas de nosso ponto de vista, como pares dialéticos que se associam mutuamente. Uma delas se apresenta na relação entre os saberes do conhecimento científico e os saberes pedagógicos. Todos os professores mencionaram a necessidade do domínio desses dois campos de saberes para que a prática docentes possa contribuir, de forma significativa, na formação do licenciando em química. Outra categoria empírica revelou-se na dinamicidade do currículo. Os professores destacaram que este instrumento organizador dos saberes e orientador das práticas de formação, transita no movimento da permanência e da transitoriedade. Aspectos que necessitam estar sempre presentes, relacionados aos saberes e outros aspectos relacionados a outros e novos conhecimentos que devem e podem ser incorporados ao currículo e servir de aprofundamento da qualidade do ensino. A terceira questão relacionada à prática pedagógica sendo compreendida como a relação entre o planejamento da prática pedagógica e a espontaneidade das atividades que surgem de maneira imprevista no cotidiano da regência. E por fim, uma categoria bastante interessante surgiu na relação entre o que se supõe ausente no consciente do currículo, e as atitudes docentes como conteúdos de formação profissional.

Compreende-se que as atividades de pesquisa contribuem, de forma significativa, na independência intelectual do estudante, bem como na formação de valores, como a disciplina acadêmica e o comprometimento com as tarefas de construção assumidas, por ocasião do processo investigatório desenvolvido. De nosso ponto de vista a atividade de pesquisa potencializa a formação de valores e a constituição, no estudante-pesquisador, de uma prática social comprometida com os valores de uma sociedade orientada pelos princípios democráticos. Neste sentido, a atividade de pesquisa foi significativa na formação do estudante. A responsabilidade e o compromisso com as atividades evidenciaram o potencial que esta atividade acadêmica carrega e pode contribuir na formação. Ao mesmo tempo, o contato com o conhecimento acadêmico por meio da atividade de leituras de textos e discussões coletivas, contribuíram para a elevação do nível intelectual e acadêmico do estudante/ pesquisador envolvido nesta pesquisa.

Com relação à contribuição para o IFPE, esperamos, também, que o conhecimento construído nesta pesquisa possa subsidiar as reflexões existentes no âmbito do curso de licenciatura em química, em torno das práticas pedagógicas e dos componentes curriculares que estruturam a 
formação oferecida e que contribuem, em última instância, para ajudar a definir o perfil de formação do licenciando. Percebe-se uma preocupação constante com a qualidade da formação a ser oferecida e o envolvimento dos professores parece indicar uma dinâmica de atuação que propicia o debate nos espaços acadêmicos. As aproximações conceituais e políticas que norteiam a fala docente, parece ser indicativo da presença constante do diálogo. As distâncias parecem expressar itinerários distintos de formação dos docentes/formadores. Talvez seja possível perceber um olhar mais "pedagógico", nas falas dos docentes cuja formação e atuação, se encontram nos espaços de disciplinas que, no currículo, estão associadas à formação profissional.

\section{Referências}

BARDIN, Laurence. Análise de Conteúdo. Tradução de Luís Antero Reto e Augusto Pinheiro. Lisboa: Edições 70, 1977.

BRASIL, MEC/SETEC/IFPE/Vitória de Santo Antão. Projeto Pedagógico do Curso de Licenciatura em Química, Vitória de Santo Antão - 2013.

DUARTE NETO. José Henrique. A Epistemologia da Prática: implicações para a formação de professores da educação básica. Jundiaí-SP: Paco Editorial, 2013.

FRIGOTO, Gaudêncio. O enfoque da dialética materialista histórica na pesquisa educacional. In: FAZENDA, Ivani (Org.). Metodologia da Pesquisa Educacional. $6^{\circ}$ ed. São Paulo: Cortez, 2000.

GATTI Bernadete Angelina \& BARRETO, Elba Siqueira de Sá. Professores do Brasil: impasses e desafios - Brasília: UNESCO, 2009.

LEFEBVRE, Henri. O Marxismo. 5. ed. São Paulo: Difel, 1979. 